\title{
Representations and Conceptions of Variables in Students' Early Understandings of Functions
}

\author{
Diana L. Moss ${ }^{1 *}$, Steven Boyce ${ }^{2}$, Teruni Lamberg ${ }^{3}$ \\ ${ }^{1}$ Utah State University, Tooele, Utah, USA \\ 2 Portland State University, Portland, Oregon, USA \\ ${ }^{3}$ University of Nevada, Reno, Nevada, USA

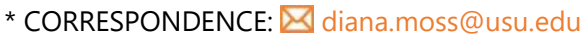

\begin{abstract}
This study explored how students develop meaning of functions by building on their understanding of expressions and equations. A teaching experiment using design research was conducted in a sixth-grade classroom. The data was analyzed using a grounded theory approach to provide explanations about why events occurred within this teaching episode and what these events mean in terms of student learning of functions (Corbin \& Strauss, 2014; Gravemeijer \& Cobb, 2006). The findings revealed that understanding functions involved integrating their understanding of different meanings of variables such as letters representing changing values and letters representing known values to model the situation using an expression, and seeing linear relationships between the independent and dependent variable through graphing. This paper provides a learning progression for supporting early understandings of functions. We discuss implications for research on students' conceptions of variables and implications for fostering functional thinking.
\end{abstract}

Keywords: linear relationships, functions, representations, early algebra

\section{INTRODUCTION}

What is a function? How do we represent a function? What do independent and dependent variables mean? What is the relationship between an algebraic equation and the graph of a function? These questions can be answered in a multitude of different ways depending on who is answering them (e.g. a student, a teacher, a mathematician, or a mathematics educator) (Thompson \& Carlson, 2017). Figure 1, adapted from Markovits, Eylon, and Bruckheimer (1986), provides a framing for the components of a function and forms for representing functions. For students to understand functions, they must be fluent in these representations, meaning that they have "the ability to translate across representations, the ability to draw meaning about a mathematical entity from different representations of that mathematical entity, and the ability to generalize across different representations" (Zbiek, Heid, Blume, \& Dick, 2007, p. 1192).

There is currently a lack of consensus on the best place to introduce function components and representations in mathematics curricula (Stephens, Ellis, Blanton, \& Brizuela, 2017). For instance, research suggests benefits for introducing algebraic representations of functional relationships early in elementary school (e.g., Blanton \& Kaput, 2011); other research suggests middle-grades students' generalizing and justifying is strengthened if they reason about quantities rather than (solely) numerical relationships (e.g., Ellis, 2007). The Common Core State Standards for Mathematics (CCSSM) prescribe a middle-ground: students are expected to represent quantitative relationships between independent and dependent variables

Article History: Received 17 May $2019 \bullet$ Revised 5 October $2019 \bullet$ Accepted 10 October 2019

(C) 2020 by the authors; licensee Modestum Ltd., UK. Open Access terms of the Creative Commons Attribution 4.0 International License (http://creativecommons.org/licenses/by/4.0/) apply. The license permits unrestricted use, distribution, and reproduction in any medium, on the condition that users give exact credit to the original author(s) and the source, provide a link to the Creative Commons license, and indicate if they made any changes. 
and relate these to an equation by sixth grade, with concepts of domain and range and understandings of the relationships between four representations of functions expected by eighth grade (National Governors Association Center for Best Practices, Council of Chief State School Officers [NGA/CCSSO], 2010).

\begin{tabular}{|c|c|c|c|c|}
\hline & & Functi & n Components & \\
\hline & & Domain & Range & Rules \\
\hline & Verbal & Verbal rule & Verbal rule & Verbal \\
\hline |: & $\begin{array}{l}\text { Arrow } \\
\text { Diagram/ } \\
\text { Table }\end{array}$ & $\begin{array}{l}\text { A circle around the } \\
\text { elements of the } \\
\text { domain/Elements of the } \\
\text { domain in a column form }\end{array}$ & $\begin{array}{l}\text { A circle around the } \\
\text { elements of the } \\
\text { range/Elements of the } \\
\text { range in a column form } \\
\end{array}$ & $\begin{array}{c}\text { Arrows/Element in domain } \\
\text { row corresponds to the } \\
\text { element in the range of the } \\
\text { same row } \\
\end{array}$ \\
\hline & Algebraic & Mathematical notation & Mathematical notation & Formula \\
\hline & Graphical & $\begin{array}{l}\text { The horizontal or x-axis } \\
\text { of a coordinate plane }\end{array}$ & $\begin{array}{c}\text { The vertical or y-axis of } \\
\text { a coordinate plane }\end{array}$ & $\begin{array}{l}\text { A set of points on the } \\
\text { coordinate plane }\end{array}$ \\
\hline
\end{tabular}

Figure 1. Function representations and function components

The work presented in this article is part of a larger study whose overarching aim was to explore how sixthgrade students develop understandings of algebraic expressions and equations (Moss \& Lamberg, 2019). In the context of a whole-class teaching experiment (Cobb, Confrey, diSessa, Lehrer, \& Schauble, 2003), we investigated how sixth-grade students developed early understandings of functions by extending their concepts of variables and their representations. The goal of the study was to document and understand how sixth-grade students think mathematically when presented with functional tasks in a teaching experiment. The aim of this paper is to present a realized learning trajectory that can be used by teachers and curriculum developers to support student understanding of representing and analyzing quantitative relationships between independent and dependent variables across different representations.

\section{THEORETICAL FRAMEWORK}

\section{Correspondence and Covariation}

Smith (2008) defines functional thinking as "representational thinking that focuses on the relationship between two (or more) varying quantities, specifically the kinds of thinking that lead from specific relationships (individual incidences) to generalizations of that relationship across instances" (p. 143). Consider the problem, "What is the relationship between the number of eyes that a group of dogs has and the number of dogs?" (Blanton, 2008). In this problem, one quantity is directly related through a specific correspondence to another quantity. The correspondence relationship in this problem is for every dog, there are two eyes, or $e$ $=2 d$ where $e$ is the number of eyes and $d$ is the number of dogs. Describing this relationship with words and variables is an important precursor for the study of algebra in the middle grades where students begin to more formally study linear functions (Blanton, Levi, Crites, \& Dougherty, 2011). Another aspect of a transition to functional thinking is describing covariational relationships about how quantities change together. Describing a covariational relationship in this problem might involve reasoning that "if we add one more dog to the group, the number of eyes in the group increases by two".

Word problems with contexts that encourage students to engage in functional thinking contain explicit scenarios that determine and allow for unknown quantities in the problem to vary. The representations that are used to communicate relationships influence the functional reasoning employed by students (Caddle \& Brizuela, 2011; Duvall, 2006). For instance, the variables in the eyes per dog algebraic representation $(e=2 d)$ might be interpreted as specific unknown or known values instead of variables that vary, depending on the representation. A function table representation may connote variables as known values, whereas in the algebraic representation $(e=2 d)$, the variables are interpreted as unknown values (see Figure 2).

\begin{tabular}{|c|c|}
\hline \multicolumn{2}{|c|}{ Table Representation } \\
\hline$d$ & $e$ \\
\hline 1 & 2 \\
\hline 2 & 4 \\
\hline 3 & 6 \\
\hline 4 & 8 \\
\hline
\end{tabular}

Figure 2. Example of a table representing known values of a function 
The eye and dog task provides opportunity to reason about discrete covariation between two variables. If the problem were changed to, for example, "If Blake swims twice as fast as Adrienne, then how fast does Blake swim?", then the context of the problem would allow the variables to vary continuously, meaning that when a quantity has different values, it changes from one to another by assuming all intermediate values (Saldanha \& Thompson, 1998; Thompson, 1995). Thompson and Carlson (2017) offer the following meaning of function based on covariational reasoning:

A function, covariationally, is a conception of two quantities varying simultaneously such that there is an invariant relationship between their values that has the property that, in the person's conception, every value of one quantity determines exactly one value of the other. (p. 436).

To develop this robust understanding of function needed for calculus, students must begin to coordinate a change in one continuously varying quantity with a change in another continuously varying quantity (Carlson \& Oehrtman, 2005).

\section{Functional Thinking in the Elementary Grades}

Elementary mathematics teachers can help support children's functional thinking by providing children with opportunities to think about variables as varying quantities (Blanton et al., 2011). Reasoning about unknown quantities, such as comparing equivalent or nonequivalent quantities, can begin as early as grade 3 (Dougherty, 2008). For instance, comparing the number of kids in Class A to the number of kids in Class B as $\mathrm{A}>\mathrm{B}$, or $\mathrm{B}<\mathrm{A}$, or $\mathrm{A}=\mathrm{B}$, promotes students to think about properties of equality (a prerequisite to learning algebra) and provides practice in quantitative reasoning that is essential for understanding functions. According to Blanton, Brizuela, Gardiner, Sawrey, and Newman-Owens (2015), young elementary students can represent function rules between covarying quantities. The National Research Council (2001) also report that children in the elementary grades "can observe that over time and across different circumstances, numerical quantities can vary in principled ways... They can learn about functions by studying how a change in one variable is reflected in the behavior of another" (p. 280).

\section{Representational Fluency in Functional Thinking}

Learning algebra includes relating symbolic systems to real-world situations, graphs and tables, or arithmetic patterns (Kirshner, 2001). Moreover, students in middle school should know how to use algebraic models or representations to symbolize quantitative relationships (NGA/CCSSO, 2010). Placing an algebra problem in context helps students make sense of the mathematics and supports conceptual understanding of abstract representations (Earnest \& Balti, 2008). "An understanding of the meanings and uses of variables develops gradually as students create and use symbolic expressions and relate them to verbal, tabular, and graphical representations" (NCTM, 2000, p. 225). Thus, conceptions of variables are developed via connecting representations that will eventually symbolize functional relationships.

\section{Students' Thinking about Variables}

Research in algebra shows that students have difficulty interpreting letters as variables that represent more than one value, and studies have focused on how students' symbolizing becomes more abstract (Moss \& Lamberg, 2019; National Research Council, 2001; Radford, 2014). Letters that represent unknowns or constants are used in algebraic equations where the main goal is to simplify or solve. Variables as varying quantities are seen in equations where variables are arguments such as in $y=x+2$. A person can use a symbol to represent a quantity that never varies (a constant), as having a value that changes from setting to setting (a parameter), or has a value that varies within a setting (a variable) (Thompson \& Carlson, 2017). Often, students ignore a variable completely (Küchemann, 1978), treat a variable as a label for an object or icon (McNeil et al., 2010; Stacey \& Macgregor, 1997), and frequently believe a variable is a specific unknown (Kuchemann, 1978; Stacey \& Macgregor, 1997). These conceptions can impact students' functional thinking.

Understanding the different meanings of variables is not a natural process. When students encounter different problem types that have different meaning of variables embedded in the context they become confused. Therefore, explicitly addressing the meaning of the variable helps students make sense of the problem context and meaningfully use the variable to solve problems (Moss \& Lamberg, 2019). Therefore, two research questions that guided this study are: (a) What was the realized learning trajectory that emerged when learning functions? and (b) What is the role of student conceptions of variables in functional thinking? 


\section{METHODOLOGY}

Twenty-two students from a sixth-grade classroom in an urban elementary school in the western region of the United States participated in the study. The students included a total of 22 predominately Latino(a) students, ages 11 to 12 . There were 11 female and 11 male students. The majority of the students were from lower to middle socioeconomic backgrounds. The classroom teacher had a master's degree in education and had taught fifth and sixth grades for two years.

We conducted a four week whole class teaching experiment in a sixth-grade classroom using a design research approach (Lamberg \& Middleton, 2009). Design research has been increasingly used in research in education to "deal with messy situations, multiple dependent variables, and develop theories about domain specific learning processes within a social context using flexible design revisions" (Lamberg \& Middleton, 2009, p. 233). The goal of design research is to address a problem in practice through an intervention, and it strives to inform the work of others through building theory and developing systematic investigations (Anderson \& Shattuck, 2012; McKenney \& Reeves, 2013; Walker, 2006).

The design for students' learning can involve a few lesson plans, a unit plan, or a whole curriculum. Design research relates to a classroom setting as it is flexible, allowing for daily adjustments to the lessons and microexperiments. Design research in a mathematics classroom allows researchers to directly study how students reason and learn mathematics (Cobb, Confrey, diSessa, Lehrer, \& Schauble, 2003).

A hypothetical learning trajectory (Simon, 1995) is a model of student learning that consists of the goal for students' learning, the tasks that will be used to promote students' learning, and hypotheses about the process of this learning. A learning trajectory explains what occurred in the research with respect to the goal of promoting learning, why it happened, and how it happened. The outcomes are the learning trajectories that specify critical understandings of the mathematical content and map out tasks that hypothetically move students to deeper understandings of that content (Lamberg \& Middleton, 2009).

The first author designed a curriculum unit on expressions, equations and functions based on a review of research and laid out a hypothetical learning trajectory for learning expressions, equations, and functions (Moss, 2014). The teacher taught the lessons and worked collaboratively as a research team member to provide input and debrief daily about the lesson. To introduce an equation containing two variables (up until this point, students had been working with one-variable equations), the class was presented with a task with the context of a soccer square, where soccer players decide the distance between each cone and create a square to practice kicking the ball. The Soccer Square Problem is in Figure 3.

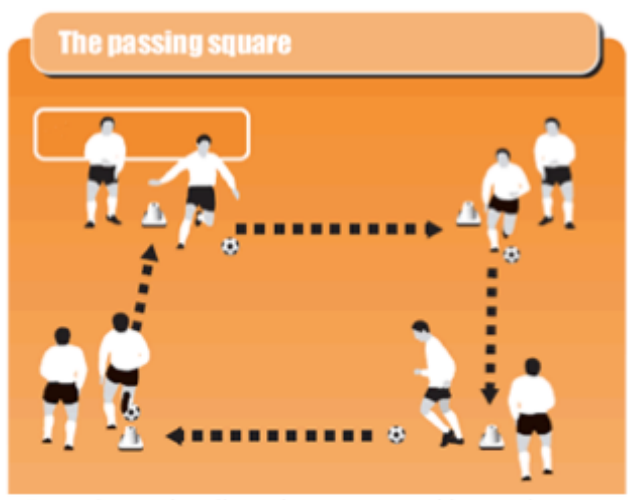

Image Source: http://www.bettersoccercoaching.com/ Article-1030-57-Soccer-Drills--Skills-Passing-drills-Passingsquare-soccer-drill
- How far away should the cones be placed?

- Should the cones be placed with the same distance in between them?

- What is the perimeter of a square?

- Find a formula for the perimeter of a square without knowing the distance between each cone.

Figure 3. The Soccer Square Problem and questions for students

The context of the soccer square was chosen because many of the students in the class enjoyed and regularly played soccer at recess. Because functional thinking involves "generalizing relationships between quantities; representing those relationships, or functions, in multiple ways using natural language, formal algebraic notation, tables, and graphs; and reasoning fluently with these representations" (Stephens et al., 2017, p. 144), it is important that students were familiar with how quantities vary in the task. The context of the soccer square also promoted students to think about writing a formula for the perimeter of a square in which the distance between the cones is unknown and recognize that there is more than one way to represent this relationship. The goals of this activity were to help students see a relationship between two variables and 
to represent the perimeter of the soccer square verbally, with an arrow diagram, algebraically, and graphically (see Figure 1, Markovits et al., 1986). As a whole class, the teacher and students discussed questions 1 through 3 in the Soccer Square Problem. Students worked in groups to find a formula for the perimeter of a square without knowing the distance between each cone through using an arrow diagram, a algebraic formula, and a graph. Then, the teacher facilitated a whole class discussion among the students.

Data sources for this teaching episode included field notes (Maxwell, 2005), video recordings, and documentation of anything that occurred in the classroom such as students' work and researchers' reflections. The data was analyzed prospectively throughout the whole class teaching experiment and retrospectively after the teaching experiment was complete. The data was analyzed using a grounded theory approach to provide explanations about why events occurred within this teaching episode and what these events mean in terms of student learning of functions (Corbin \& Strauss, 2014; Gravemeijer \& Cobb, 2006). The following coding scheme (Table 1) emerged from the data in the larger context of the whole class teaching experiment on how students made sense of the meaning of letters and variables (Moss \& Lamberg, 2019).

Table 1. Types of Thinking about Letters that Emerged from the Larger Context

\begin{tabular}{|c|c|}
\hline $\begin{array}{l}\text { Types of Thinking about Letters and } \\
\text { Variables }\end{array}$ & $\begin{array}{l}\text { Examples of problem contexts that show these Types of } \\
\text { Thinking }\end{array}$ \\
\hline $\begin{array}{l}\text { Letters represents labels of categories, where each } \\
\text { letter represents a categorical unit }\end{array}$ & $\begin{array}{l}\text { Students count the total number of M\&M's from a small bag. Write an } \\
\text { expression to find the total amount of red and green M\&M's. }\end{array}$ \\
\hline and & 3 red and 2 green expression $3 r+2 g$ \\
\hline Letters represent labels of known quantities & 3 red and 2 green expression $r+g$ \\
\hline Letters represent changing values & $\begin{array}{l}\text { Find the price for } 4 \text { packs of cupcakes and a single gallon of milk (e.g., } \\
4 c+s) \text { at different stores (given that the prices are different at each } \\
\text { store) }\end{array}$ \\
\hline Letters represent known values. & $\begin{array}{l}\text { Given } c=2 \text { and } s=3 \text {, substitute values to solve the problem } 4 c+s \text { (e.g., } \\
4(2)+3=11)\end{array}$ \\
\hline Letters represent an unknown value & Given $x+5=11$, balance the equation to solve for $x$ \\
\hline and & $x=6$ \\
\hline \multicolumn{2}{|l|}{ Letters represent a known value } \\
\hline $\begin{array}{l}\text { Letters represent a varying quantity } \\
\text { and } \\
\text { Letters represent a co-varying quantity }\end{array}$ & $\begin{array}{l}\text { Find a formula for the perimeter of a square. Substitute a value for } \\
\text { the side distance of the square to find the perimeter of the square. } \\
4 s=p \text {, when } s=1 \text {, then } p=4 \text {, when } s=2 \text {, then } p=8 \text {, etc. As } s \text { increases by } \\
1, P \text { increases by } 4 \text {. }\end{array}$ \\
\hline
\end{tabular}

\section{RESULTS}

The learning trajectory that emerged included visualizing and modeling the problem context with an equation, exploring the relationship between an independent and dependent variable by creating an arrow diagram, graphing the data, and making connections that a function represents a relationship between the independent and dependent variable as illustrated in Figure 4. The large rectangle is the target CCSSM for sixth-grade expressions and equations that introduces the relationship between independent and dependent variables (NGA/CCSSO, 2010). The smaller rectangles represent the realized learning trajectory that emerged to make sense of functions. The next section expands on this learning trajectory and provides examples of the learning activities.

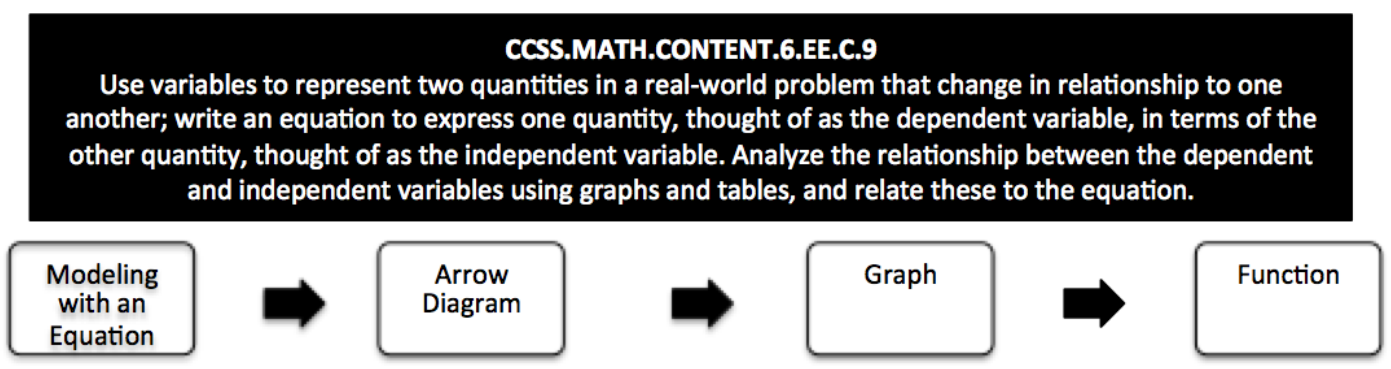

Figure 4. The Soccer Square Problem and questions for students 


\section{Modeling a Problem Context with an Equation}

Students modeled the problem context and wrote an equation to represent how they visualized the situation. They determined that since the soccer field is a square, it has equal side lengths. Modeling the problem context contributed to their sense making. The understanding emerged as students engaged in a discussion in relation to the problem context of the square soccer field that must have sides of the same length. In addition, they needed to figure out that they were trying to find the perimeter. This process involved integrating how to represent the concept of perimeter, as experienced in the problem context, as an expression of $4 s$ that determined the total length of the perimeter. The independent variable was the length of the side $(s)$. The dependent variable was the perimeter $(p)$. Students wrote an equation to represent the relationship between the side lengths and the perimeter. Exploring this relationship involved thinking about the length of a side of the soccer field that can change its value and impact the size of the perimeter. The following discussion among the teacher and students shows students coming to an understanding that the side lengths have to be equal in a soccer square.

Teacher: $\quad$ Based on the picture and the video, how far away should the cones be placed?

Jenn: $\quad$ Equal sides. a square has equal sides.

Teacher: So, what does this mean?

Chris: $\quad$ Same distance

Teacher: And that makes it equal sides. And why do they have to be equal?

Chris: Because a square has equal sides.

Teacher: Anyone else?

Lisa: $\quad$ I think the cones should be $10 \mathrm{ft}$ away from each other?

Teacher: $\quad$ Like $10 \mathrm{ft}$ on one side and 12 on another?

Lisa: $\quad$ No, like $10 \mathrm{ft}, 10 \mathrm{ft}, 10 \mathrm{ft}$, and $10 \mathrm{ft}$

Teacher: Why should they all be 10 ?

Mary: $\quad$ It's like a square.

Eric: $\quad$ It has to be equal sides because otherwise it would be another shape.

Teacher: What is a perimeter of a square?

Owen: $\quad$ Around the outside

Teacher: So those distances around the outside.

Students made meaning of the soccer square as having four equal sides and the length of the sides had to be the same because it is a square. For example, another student in the class, Ingrid, illustrated how each side of the soccer field was represented by an $s$ (see Figure 5). The $s$ represented the length of one side of the soccer field.

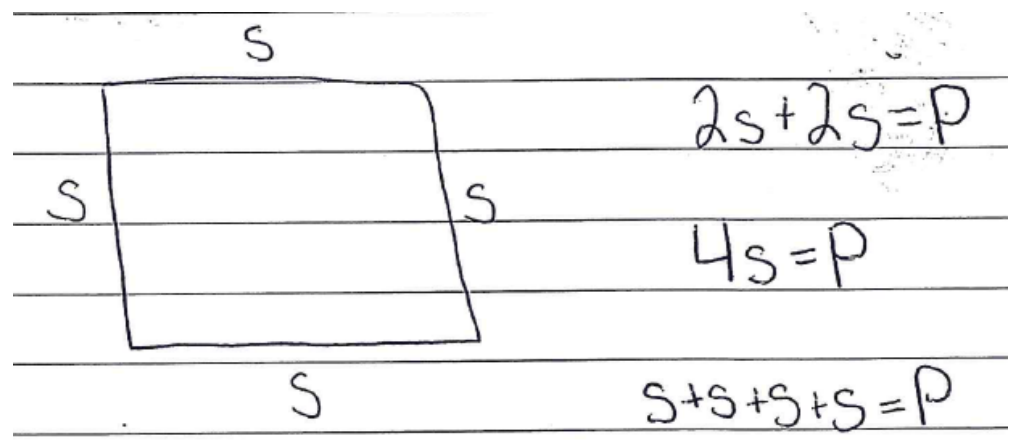

Figure 5. Ingrid's work of modeling with an equation 
In Ingrid's representation of the equation, she used a formula with the letters $s$ and $P$ to label side and perimeter. The $s$ represented the category of the side length of the field. When she wrote $s+s+s+s=P$ and $2 s+2 s=P$. She used the letter $s$ as representing the length of a side that is a changing value depending on the context. The equation represented how to calculate the perimeter of a particular soccer square by replacing each letter $s$ with the same number in the equation. The equation also indicates that a relationship exists between the quantities of side length and perimeter.

Students in the class indicated that there was more than one way to represent the perimeter of the square using an equation. Therefore, they had a flexible understanding of the meaning of the variable and how to model the problem. The following dialog represents how students modeled the problem situation and wrote an equation.

Teacher: What is one of the equations you came up with?

Jake: $\quad 4 s=P$

Chris: $\quad n$ times four equals $p$

Eric: $\quad a+a+a+a$ equals $P$

Mary: Also known as $4 a$

Lisa: $\quad 4 x=P$

Teacher: Are there any others without just changing the variable?

Ingrid: $\quad 2 x+2 x=P$

Although Ingrid used $s$ and $P$ in her written work, she called out that her equation is $2 x+2 x=P$. This suggests that Ingrid understands the equivalence of the formulas $2 s+2 s=P$ and $2 x+2 x=P$ and $4 x=P$ and also confirms that Ingrid did not use $s$ solely as a label for side.

In Figure 6, Eric drew a square with side lengths of 20 and wrote the equations $A+A+A+A=D$ and $4 A$ $=$ D. Eric assigned a specific value of 20 for each side length. Therefore, his initial drawing indicated that he was thinking about a particular soccer square. However, he wrote the formula below to model the problem situation. He was also thinking abstractly about the problem context representing changing values that he could find using his equation.

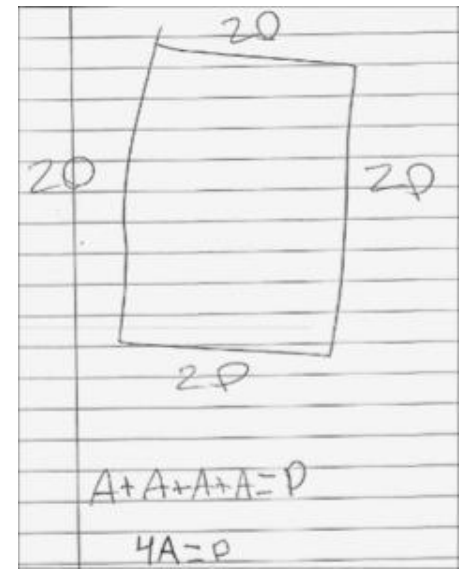

Figure 6. Eric's work of modeling with an equation

\section{Arrow Diagram}

As a whole class in the next phase of the instructional sequence, students came to an agreement to use the equation for a perimeter of a square of $4 s=P$. The teacher introduced the components of an arrow diagram (i.e. inputs, outputs, domain, range). Students were asked to create an arrow diagram for the equation of the perimeter of a square. To create the arrow diagram, students conceptualized a letter as representing a known value, an unknown value, and a changing value. Students began reasoning about known and unknown values through thinking about inputs and outputs. Eric's work is shown in Figure 7. 


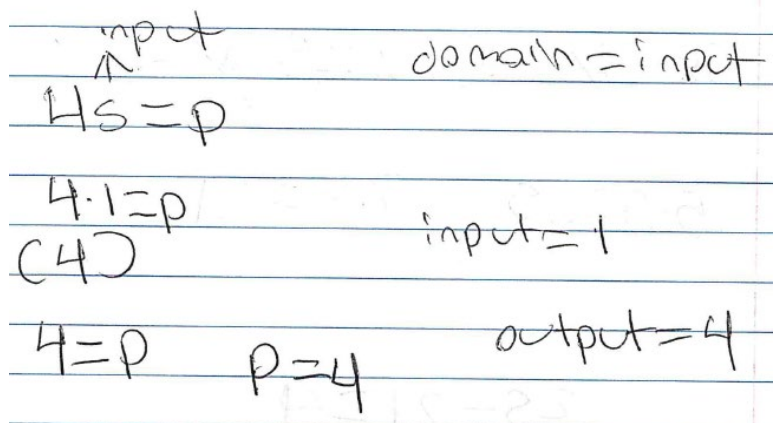

Figure 7. Eric's work of determining inputs and outputs

Eric labeled the $s$ as the input and the $p$ as the output. He wrote input=1. He understood that if $s=1$, it can be substituted into the problem to figure out the output of four ( 4 times $1=p$ ). This required understanding that the letter $s$ can represent the known value of 1 . When the value is known, it no longer needs to be represented with a letter and could be substituted to solve for $p$. The letter $p$ represented an unknown value and, subsequently, a changing value, in the problem. The $p$ also represented the output. The students were connecting that the domain represented the inputs that impacted the outputs.

After most students had completed their own arrow diagrams, the teacher provided the students with the inputs and asked for the outputs during a whole class discussion to clarify the idea of inputs and outputs for all students in the class. Figure 8 shows a class representation of the arrow diagram for the function $p=4 s$ that emerged through a discussion of inputs and outputs. Eric again substituted the input, 2, for $s$ and found 8 for $p$.

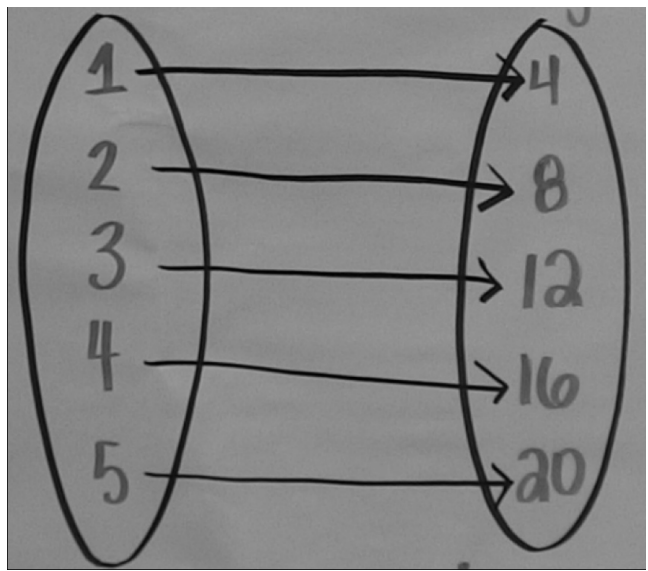

Figure 8. The class representation of an arrow diagram for the function $p=4 s$

Teacher: I'm going to tell you what the input is, and you raise your hand if you know what the output is. My input is 1 , what is my output?

Gina: $\quad 4$

Teacher: My input is 2, what is my output?

Eric: $\quad 8$

Teacher: My input is 3, what is my output?

Lisa: $\quad 12$

Teacher: My input is 4, what is my output?

Britney: $\quad 16$

[Teacher and students continue through input of 6]

With the arrow diagram, the context of the soccer square is further removed and letters are replaced with a different (verbal) label: "input" means $x, s$, or $a$, and "output" means $p$. In this scenario, there is an implicit rule for the inputs given by counting numbers: $1,2,3,4,5$. At this point, students were performing calculations to find outputs for known values. They were not explicitly thinking about the functional relationship between 
the numbers (inputs and outputs) and were not necessarily reasoning about the letters as representing varying quantities.

\section{Graph}

In a subsequent teaching session, students were given a table of points and asked to plot the points on a Cartesian plane and draw a line through the points. Then, students were asked to explain why the line that they drew is represented by $y=x+3$. The students were tasked with graphing the ordered pairs $(0,3),(2,5)$, $(4,7)$, and $(6,9)$ and then connecting them with a line. Figure 9 displays Frank's, Eric's, and Chris' answers about why the graph of a set of ordered pairs corresponds with the equation $y=x+3$.

\begin{tabular}{|c|c|}
\hline \multicolumn{2}{|r|}{$\begin{array}{c}\text { This (the graphed line) is the line } y=x+3 \text {. Can you explain why? } \\
\text { (Students' responses are replicated below:) }\end{array}$} \\
\hline Frank & $\begin{array}{l}y=x+3 \\
y=0+3\end{array}$ \\
\hline Eric & $\begin{array}{l}\text { This line is } \mathrm{y}=\mathrm{x}+3 \text { because } \mathrm{x} \text { is } 0 \text { and } 0+3=3 \text { and } \mathrm{y}=3 \\
3=3\end{array}$ \\
\hline Chris & $\begin{array}{c}\text { This is because If } \mathrm{x} \text { is } 0 \mathrm{y} \text { is } 3 \text {, if } \mathrm{x} \text { is } 2 \mathrm{y} \text { is } 5 \text {. This can keep going with the same operation. } \\
\text { This is why the line is } \mathrm{y}=\mathrm{x}+3\end{array}$ \\
\hline
\end{tabular}

Figure 9. Frank's, Eric's, and Chris' answers about why the graph of a set of ordered pairs corresponds with the equation $y=x+3$

Frank, Eric, and Chris each correctly plotted the four points and connected the points with a line. In Frank's explanation of why the equation $y=x+3$ represents the line, he indicated that he substituted the input of 0 for $x$ into the equation. Eric's explanation includes further justification that the output value of 3 in the equation $y=x+3$ after substituting $x=0$ agrees with the line including the point $(0,3)$.

When students graphed the points and explicitly looked at the trends in the data they started to engage in functional thinking as a covarying (Confrey \& Smith, 1994; Saldanha \& Thompson, 1998) relationship between the numbers. These students noticed that the larger the input, the greater the perimeter and thought about the relationship between the changing values, the input, and the output that represented an unknown value. This process of noticing trends reinforced the meaning of the letter for the input as a varying quantity.

Chris' explanation (Figure 9) describes his reasoning about a correspondence between multiple input and output values. He focused on the relationship between known $x$-values and known $y$-values (that the $y$-values were three larger than the $x$-values), a correspondence relationship. Chris wrote, "keep going with the same operation", which suggests that he has begun to generalize the relationship between inputs and outputs. For example, if Chris was provided with the input value of 7 , then he would be able to find the output value of 10 using the equation $y=x+3$.

The points that Chris plotted each have the $x$-values increasing by 2 . If he were considering variation in the $y$-values (that they increase by 2), he would be engaging in (discrete) variational reasoning (Thompson \& Carlson, 2017). Despite drawing the line, his explanation certainly does not suggest he has considered continuous variation, as he does not explain what would happen if $x$ were not an integer, such as the decimal 1.3 .

\section{Function}

In the last stage of the instructional sequence, students began to understand that how the dependent variable, $y$, changes depends on the independent variable, $x$. The short excerpt below shows how students began to reason about correspondence with functions in a whole class discussion facilitated by the teacher.

Teacher: What if I tell you that my x coordinate is 1 . What am I going to do?

Joanna: Add

Teacher: Add what?

Joanna: Add the $\mathrm{x}$

Teacher: $\quad$ So I have $\mathrm{y}=1+3$. Can I solve?

Class: $\quad \mathrm{y}=4$ 
Gina: $\quad U m$, so I just don't get how you got the numbers for $\mathrm{x}$.

Eric: $\quad$ The coordinates. If this is a variable for 0 then $\mathrm{y}$ is a variable for 3

Teacher: Gina, if I look at this and let's say I pick $\mathrm{x}$ is 1 , and we chose $\mathrm{x}$ is 1 , then Joanna said $1+3$ equals 4 . Does that fall onto the line that I drew? If I plot that and plug that into my equation, so y equals 4 , does that plot on the same line?

Class: $\quad$ Yes

Teacher: What if I say $\mathrm{x}$ is 3 ?

Gina: $\quad$ That would be 6

Teacher: $\quad 6$, right. If I go up 6, does that fall on that line?

Class: $\quad$ Yes

Teacher: Do I see a pattern here?

Class: $\quad$ Yes

Teacher: $\quad$ If I pick any number for $\mathrm{x}$ and plug it into my equation for $\mathrm{y}$, will it fall on my line?

Class: $\quad$ Yes

Teacher: $\quad$ So, if I say $\mathrm{x}$ equals 5 and I plug it into my equation over there so $\mathrm{x}$ equals 5 , and $\mathrm{y}$ is $\mathrm{x}+3$, what would y equal?

Jake: $\quad$ y would be 8

Teacher: Let's see if that falls on my line here. Do you see that pattern? Does anyone know what that is called? When we have an equation and use it for this?

Eric: Function

Most students made arrow diagrams with inputs and outputs and understood how to graph a line through the coordinates. The context lent itself to continuous data; however, students only worked with discrete data. Chris (Figure 9) understood the generality of the relationship between independent and dependent variables, varying and co-varying quantities, espousing a view of a relation as a repeatable input-output process (Dubinsky \& Harel, 1992; Smith, 2008).

\section{CONCLUSIONS AND IMPLICATIONS}

The progression of learning functions involved learning to model the problem context and represent the situation as an equation. During this process students had to understand the different meanings of letters: letters represents changing values, known values, unknown values, varying quantities, and co-varying quantities. Students reasoned about these representations in different ways depending on their conceptions of letters and variables within the problem context as described in Table 1.

Learning functions involved integrating these different types of thinking about letters and variables. The phases of functional development involved being able to model a situation and represent it as an equation. The ability to calculate input and output in the problem context involved a correspondence relationship (Blanton, 2008; Rizzuti, 1991). This process involves substituting numbers for the independent variable in the equation in order to calculate the dependent value. Functional thinking occurred when patterns and trends between the input and output became apparent through graphing. In the graph of the line $y=x+3$, as the input, $x$, increases, the output, $y$ also increases.

Functional thinking was introduced after learning about expressions and equations. During the teaching of expressions and equations, students developed an understanding of how to model situations using letters and variables and also explicitly thought about the meaning of variables. Therefore, when they encountered functions, they were attending to multiple meanings of letters and variables. The understanding of the different meanings of letters and variables in expressions and equations (see Figure 3) was critical for sixthgrade students to successfully understand functions. Students that thought about letters as representing labels of categories did not engage in thinking about functions where letters represent changing, known, unknown, and varying and covarying quantities. Using the function for perimeter of a square, $P=4 s$, Table 2 shows types of thinking about letters and variables in $P=4 s$ for sixth-grade students. 
Table 2. Types of thinking about letters and variables in $P=4 s$ for sixth-grade students

\begin{tabular}{|c|c|c|c|}
\hline $\begin{array}{l}\text { Types of Thinking about } \\
\text { Letters and Variables }\end{array}$ & \multicolumn{2}{|c|}{$\begin{array}{l}\text { Types of Thinking about Letters and } \\
\text { Variables in } P=4 s\end{array}$} & $\begin{array}{l}\text { Example of Mathematical } \\
\text { Behavior }\end{array}$ \\
\hline \multirow{2}{*}{$\begin{array}{l}\text { Letters represent labels of } \\
\text { categories }\end{array}$} & \multicolumn{2}{|c|}{$P$ is Perimeter and $s$ is side } & None \\
\hline & \multicolumn{3}{|c|}{ Perimeter is equal to 4 sides } \\
\hline \multirow{2}{*}{$\begin{array}{l}\text { Letters represent labels of } \\
\text { known quantities }\end{array}$} & \multicolumn{2}{|c|}{ Perimeter $(P)$ is 8 and side $(s)$ is 2} & \multirow{2}{*}{$\begin{array}{l}\text { Replacing Perimeter }(P) \text { with } 8 \text { and } \\
\text { sides }(s) \text { with } 2\end{array}$} \\
\hline & \multicolumn{2}{|c|}{$\begin{array}{l}\text { Perimeter is equal to } 4 \text { sides or } 8 \text { is equal to } 4 \\
\text { sides of length } 2\end{array}$} & \\
\hline \multirow{7}{*}{$\begin{array}{l}\text { Letters represent changing } \\
\text { values } \\
\text { Letters represent known values }\end{array}$} & \multicolumn{2}{|c|}{ If $P=4 s$} & \multirow{7}{*}{$\begin{array}{l}\text { Given a sequence of values for } s, \\
\text { filling in an arrow diagram or table } \\
\text { with the corresponding value of } P \text { by } \\
\text { successively substituting the values } \\
\text { into the equation } P=4 s \text { and } \\
\text { simplifying. }\end{array}$} \\
\hline & $\begin{array}{r}s \\
\end{array}$ & $P$ & \\
\hline & 1 & 4 & \\
\hline & 2 & 8 & \\
\hline & 3 & 12 & \\
\hline & \multicolumn{2}{|c|}{$\begin{array}{l}\text { The side lengths of a given square can change, } \\
\text { which changes the perimeter of the square. }\end{array}$} & \\
\hline & \multicolumn{2}{|c|}{$\begin{array}{l}\text { If } \mathrm{s} \text { is } 1 \text {, and } P=4 s \text {, then } P=4 . s \text { and } \mathrm{P} \text { are known } \\
\text { values. }\end{array}$} & \\
\hline \multirow{2}{*}{$\begin{array}{l}\text { Letters represent unknown } \\
\text { values } \\
\text { Letters represent known values }\end{array}$} & \multicolumn{2}{|c|}{ Given $P=12$ and $P=4 s$, then $12=4 s$, so $s=3$} & Solving for a previously unknown \\
\hline & \multicolumn{2}{|c|}{$\begin{array}{l}\text { In the equation } 12=4 s, s \text { is an unknown value. } P= \\
12 \text { and } s=3 \text { are known values. }\end{array}$} & $\begin{array}{l}\text { value, } s \text {, in } 12=4 s \text {, so that } s \text { becomes } \\
\text { equal to } 3 \text {, a known value. }\end{array}$ \\
\hline \multirow{4}{*}{$\begin{array}{l}\text { Letters represent varying } \\
\text { quantities } \\
\text { Letters represent co-varying } \\
\text { quantities }\end{array}$} & \multicolumn{2}{|c|}{$\begin{array}{l}\text { Substituting any value for the side length of the } \\
\text { square to find the perimeter of the square. }\end{array}$} & $\begin{array}{l}\text { Filling in both sides of an arrow } \\
\text { diagram or table for } s \text { and } P \text { in the }\end{array}$ \\
\hline & \multirow{2}{*}{\multicolumn{2}{|c|}{$\begin{array}{l}\text { In the equation } 4 s=P \text {, when } s=1 \text {, then } P=4 \text {, when } \\
s=2 \text {, then } P=8 \text {, etc. As } s \text { increases by } 1, P \text { increases } \\
\text { by } 4 \text {. }\end{array}$}} & equation $P=4 s$ \\
\hline & & & $\begin{array}{l}\text { Graphing the line of } P=4 s \text { by plotting } \\
\text { points. }\end{array}$ \\
\hline & \multicolumn{2}{|c|}{$\begin{array}{l}\text { The Perimeter of a square }(P) \text { varies as the side } \\
\text { length of the square }(s) \text { varies. }\end{array}$} & \\
\hline
\end{tabular}

Teachers can anticipate students' mathematical behavior and types of thinking about letters and variables to plan and modify lessons (e.g. Table 2). Although objectives for teachers of what students are expected to learn are provided in the CCSSM (NGA/CCSSO, 2010), teachers need to know the big mathematical ideas and be able to present these as interconnected topics (Ma, 2010). In our results, the anticipated mathematical idea was learning the different representations of functions: modeling with an equation, arrow diagram, graph, and function (Figure 4), as determined by the CCSSM (NGA/CCSSO, 2010). However, the findings of this study suggest that the types of thinking about letters and variables strongly influenced students' thinking of functions. Teachers need to help students to make connections between the types of thinking about letters and variables in order to learn functions.

We offer two ways in which prior research identifying the importance of learning about the different meanings of variables (Blanton, 2008; McNeil et al., 2010; Phillip, 1992) might be leveraged to improve upon the design described in this study. One area for potential improvement is being cognizant of whether the context of a problem engages students in a discussion of discrete functions versus continuous functions. Van de Walle, Karp, and Bay-Williams (2015) states that "the discussion of functions, especially graphical representations, should include a discussion of whether the points plotted on the graph should be connected or not and why" (p. 353). The context of the problem dictates whether or not the points should be connected. In the graphing example of the learning progression, all values along the line were solutions to the function. However, since the students were only exposed to isolated or selected values in the context for the sides of the soccer square, they did not consider whether the function is continuous. Future teaching experiments should explore a similar context, but expose students to rational numbers as well as whole numbers and have students determine if the rational numbers make sense with the context of the problem. Students' use of rational numbers throughout the learning progression may support this understanding.

A second area of the instructional sequence that should be further explored is the sequencing of including and excluding context and in allowing letters to represent quantities that vary and co-vary. In the learning progression, letters first represent labels of categories. Letters also represented labels of known quantities and later as known, unknown, and changing values. When arrow diagrams were introduced, the understanding of letter representing a varying and co-varying quantity was emphasized. If students make connections among representations of functions through quantitative reasoning throughout the progression, they may be more likely to develop a robust understanding of functions demanded by K-12 national standards and requisite for success in college mathematics courses. 


\section{Disclosure statement}

No potential conflict of interest was reported by the authors.

\section{Notes on contributors}

Diana L. Moss - Utah State University, Tooele, Utah, USA.

Steven Boyce - Portland State University, Portland, Oregon, USA.

Teruni Lamberg - University of Nevada, Reno, Nevada, USA.

\section{REFERENCES}

Anderson, T., \& Shattuck, J. (2012). Design-based research: A decade of progress in education research? Educational Researcher, 41(1), 16-25. https://doi.org/10.3102/0013189X11428813

Blanton, M. L. (2008). Algebra and the elementary classroom: Transforming thinking, transforming practice. Portsmouth, NH: Heinemann.

Blanton, M., \& Kaput, J. J. (2011). Functional thinking as a route into algebra in the elementary grades. In J. Cai \& E. Knuth (Eds.), Early algebraization: A global dialogue from multiple perspectives (pp. 5-23). Heidelberg, Germany: Springer. https://doi.org/10.1007/978-3-642-17735-4_2

Blanton, M., Brizuela, B., Gardiner, A., Sawrey, K., \& Newman-Owens, A. (2015). A learning trajectory in 6year-olds' thinking about generalizing functional relationships. Journal for Research in Mathematics Education, 46(5), 511-558. https://doi.org/10.5951/jresematheduc.46.5.0511

Blanton, M., Levi, L., Crites, T., Dougherty, B., Zbiek, R. M., \& National Council of Teachers of Mathematics. (2011). Developing essential understanding of algebraic thinking for teaching mathematics in grades 35. Series in essential understandings. National Council of Teachers of Mathematics.

Caddle, M. C., \& Brizuela, B. M. (2011). Fifth graders' additive and multiplicative reasoning: Establishing connections across conceptual fields using a graph. The Journal of Mathematical Behavior, 30(3), 224234. https://doi.org/10.1016/j.jmathb.2011.04.002

Carlson, M., \& Oehrtman, M. (2005). Key aspects of knowing and learning the concept of function. Research Sampler Series, 9, The Mathematical Association of America Notes Online.

Cobb, P., Confrey, J., diSessa, A., Lehrer, R., \& Schauble, L. (2003). Design experiments in educational research. Educational Researcher, 32(1), 9-13. https://doi.org/10.3102/0013189X032001009

Confrey, J., \& Smith, E. (1994). Exponential functions, rates of change, and the multiplicative unit. Educational Studies in Mathematics, 26(2/3). 135-64. https://doi.org/10.1007/BF01273661

Corbin, J., \& Strauss, A., (2014). Basics of qualitative research: Techniques and procedures for developing grounded theory (4th ed.). Thousand Oaks, CA: Sage.

Dougherty, B. (2008). Measure up: A quantitative view of early algebra. In J. Kaput, D.W. Carraher, \& M. Blanton (Eds.), Algebra in the early grades (pp. 389-412). Mahwah, NJ: Lawrence Erlbaum Associates/Taylor \& Francis Group. https://doi.org/10.4324/9781315097435-18

Dubinsky, E., \& Harel, G. (1992). The nature of the process conception of function. In G. Harel \& E. Dubinsky (Eds.), The Concept of Function: Aspects of epistemology and pedagogy (pp. 85-106). Washington, D.C.: Mathematical Association of America.

Duval, R. (2006). A cognitive analysis of problems of comprehension in a learning of mathematics. Educational Studies in Mathematics, 61(1/2), 103-131. https://doi.org/10.1007/s10649-006-0400-z

Earnest, D., \& Balti, A. (2008). Instructional strategies for teaching algebra in elementary school: Findings from a research-practice collaboration. Teaching Children Mathematics, 14(9), 518-522.

Ellis, A. B. (2007). The influence of reasoning with emergent quantities on students' generalizations. Cognition and Instruction, 25(4), 439-478. https://doi.org/10.1080/07370000701632397

Gravemeijer, K., \& Cobb, P. (2006). Design research from a learning design perspective. In: J. Van den Akker, K. Gravemeijer, S. McKenney, \& N. Nieveen (Eds.), Educational design research (pp. 17-51). London, England: Routledge. 
Kirshner, D. (2001). The structural algebra option revisited. In R. Sutherland, T. Rojano, A. Bell, \& R. Lins (Eds.), Perspectives on school algebra (pp. 83-98). Dordrecht, The Netherlands: Kluwer Academic. https://doi.org/10.1007/0-306-47223-6_5

Küchemann, D. (1978). Children's understanding of numerical variables. Mathematics in School, (4), 23-26.

Lamberg, T. D., \& Middleton, J. A. (2009). Design research perspectives on transitioning from individual microgenetic interviews to a whole class teaching experiment. Educational Researcher, 38(4), 233-245. https://doi.org/10.3102/0013189X09334206

Ma, L. (2010). Knowing and teaching elementary mathematics: Teachers' understanding of fundamental mathematics in China and the United States. New York, NY: Routledge.

Markovits, Z., Eylon, B., \& Bruckheimer, M. (1986). Functions today and yesterday. For the Learning of Mathematics, 6(2), 18-24.

Maxwell, J. A. (2005). Qualitative research design: An interactive approach. Thousand Oaks, CA: Sage.

McKenney, S. E., \& Reeves, T. C. (2012). Conducting educational design research. [electronic resource]. Abingdon, Oxon, UK; New York: Routledge.

McNeil, N. M., Weinberg, A., Hattikudur, S., Stephens, A. C., Asquith, P., Knuth, E. J., \& Alibali, M. W. (2010). A is for apple: mnemonic symbols hinder the interpretation of algebraic expressions. Journal of Educational Psychology, 102(3), 625-634. https://doi.org/10.1037/a0019105

Moss, D. (2014). An investigation of student learning in beginning algebra using classroom teaching experiment methodology and design (Doctoral Dissertation). Retrieved from ProQuest Dissertations and Theses Global.

Moss, D., \& Lamberg, T. (2019). Conceptions of expressions and equations in early algebra: A learning trajectory. International Journal for Mathematics Teaching and Learning, 20(2), 170-192.

National Council of Teachers of Mathematics. (2000). Principles and standards for school mathematics. Reston, VA: Auhor.

National Governors Association Center for Best Practices, Council of Chief State School Officers. (2010). Common core state standards (mathematics). Washington, DC: Author.

National Research Council. (2001). Adding it up: Helping children learn mathematics. J. Kilpatrick, J. Swafford, \& B. Findell (Eds.). Mathematics Learning Study Committee, Center for Education, Division of Behavioral and Social Sciences and Education. Washington, DC: National Academy Press.

Philipp, R. A. (1992). A study of algebraic variables: Beyond the student-professor problem. Journal of Mathematical Behavior, 11(2), 161-176.

Radford, L. (2014). The progressive development of early algebraic thinking. Mathematics Education Research Journal, 26, 257-277. https://doi.org/10.1007/s13394-013-0087-2

Rizzuti, J. M. (1991). Students' conceptualizations of mathematical functions: The effects of a pedagogical approach involving multiple representations (Doctoral dissertation). Retrieved from ProQuest Information \& Learning. (1992-77673-001)

Saldanha, L., \& Thompson, P. W. (1998). Re-thinking co-variation from a quantitative perspective: Simultaneous continuous variation. In S. B. Berenson \& W. N. Coulombe (Eds.), Proceedings of the 20th Annual Meeting of the North American Chapter of the International Group of the Psychology of Mathematics Education (PME-NA), Raleigh, NC. Retrieved from http://www.pmena.org/proceedings/

Simon, M. A. (1995). Reconstructing mathematics pedagogy from a constructivist perspective. Journal for Research in Mathematics Education, 26, 114-145. https://doi.org/10.2307/749205

Smith, E. (2008). Representational thinking as a framework for introducing functions in the elementary curriculum. In J. Kaput, D. Carraher, \& M. Blanton (Eds.), Algebra in the Early Grades. Mahwah, NJ: Lawrence Erlbaum Associates/Taylor \& Francis Group and National Council of Teachers of Mathematics.

Stacey, K., \& MacGregor, M. (1997). Ideas about Symbolism That Students Bring to Algebra. The Mathematics Teacher, 90(2), 110-113.

Stephens, A. C., Ellis, A. B., Blanton, M., \& Brizuela, B. M. (2017). Algebraic thinking in the elementary and middle grades. In J. Cai, (Ed.) Compendium for research in mathematics education (pp. $386-420$ ). Reston, VA: National Council of Teachers of Mathematics. 
Stephens, A. C., Fonger, N., Strachota, S., Isler, I., Blanton, M., Knuth E., \& Gardiner, A. M. (2017) A Learning Progression for Elementary Students' Functional Thinking. Mathematical Thinking and Learning, 19(3), 143-166. https://doi.org/10.1080/10986065.2017.1328636

Thompson, P. W. (1995). Notation, convention, and quantity in elementary mathematics. In J. Sowder \& B. Schapelle (Eds.), Providing a foundation for teaching middle school mathematics (pp. 199-221). Albany, NY: SUNY Press.

Thompson, P. W., \& Carlson, M. P. (1995). Variation, covariation, and functions: Foundational ways of thinking mathematically. In J. Cai (Ed.), Compendium for research in mathematics education (pp. 421456). Reston, VA: National Council of Teachers of Mathematics.

Van de Walle, J. A., Karp, K., \& Bay-Williams, J. M. (2015). Elementary and middle school mathematics: Teaching developmentally. Boston, MA: Pearson.

Walker, D. (2006). Toward productive design studies. In J. Van den Akker, K. Gravemeijer, S. McKenney, \& N. Nieveen, Educational Design Research (pp. 9-18). New York, NY: Routledge.

Zbiek, R. M., Heid, M. K., Blume, G., \& Dick, T. P. (2007). Research on technology in mathematics education: The perspective of constructs. In F. K. Lester (Ed.), Second handbook of research on mathematics teaching and learning (pp. 1169-1208). Charlotte, NC: Information Age Publishing. 